\title{
ANALISIS STAKEHOLDER DALAM AGRIBISNIS BUAH NAGA DI KECAMATAN BANGOREJO KABUPATEN BANYUWANGI
}

Oleh :

\author{
ANNASTIA LOH JAYANTI *) dan MUKSIN **)
}

\begin{abstract}
ABSTRAK
Sektor pertanian masih menjadi salah satu unggulan sebagai penggerak sektor perekonomian di Indonesia, begitu juga di Kabupaten Banyuwangi yang memiliki potensi sumberdaya alam berlimpah. Salah satu komoditi hortikultura yang saat ini menjadi primadona di Kabupaten Banyuwangi adalah buah naga, dimana salah satu sentranya adalah Kecamatan Bangorejo. Permasalahan klasik yang terjadi dalam dunia agribisnis adalah rendahnya posisi tawar petani pada saat tiba musim panen yang saat ini sebagian besar produk buah naga langsung ditampung oleh pengepul beserta harga dan kualitas yang juga ditetapkan oleh pengepul. Kondisi ini dapat diperbaiki apabila ada kerjasama antara berbagai pihak yang memiliki kepentingan dan pengaruh di bidang agribisnis buah naga. Analisis stakeholder memetakan pihak yang terlibat beserta kebutuhan dan peran yang harus dijalankan masing-masing pihak tersebut dalam mendukung keberlanjutan agribisnis buah naga di Kecamatan Bangorejo Kabupaten Banyuwangi.
\end{abstract}

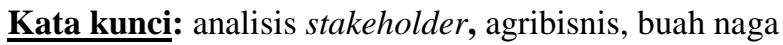

\section{PENDAHULUAN}

Kabupaten Banyuwangi secara geografis merupakan daerah yang subur dan memiliki potensi yang besar bagi peningkatan pengembangan produk pertanian, karena hampir semua komoditas pertanian khususnya tanaman pangan dan hortikultura dapat tumbuh dan berkembang. Dukungan kekayaan sumber daya alam yang melimpah serta permintaan pasar yang tinggi menempatkan komoditas hortikultura sebagai produk bernilai ekonomi tinggi, sehingga usaha hortikultura menjadi sumber pendapatan petani dan pelaku usaha lainnya dari skala mikro hingga makro di sebagian besar wilayah Kabupaten Banyuwangi (http://portal.banyuwangikab.go.id/news/detail/261 1/potensi-buah-naga-banyuwangi-menggema-di-pe njuru-jawa-timur).

Sentra produksi buah naga di Banyuwangi terdapat di Kecamatan Bangorejo, Tegaldlimo dan Purwoharjo. Produksi buah naga di Banyuwangi pada 2014 mencapai 28.819 ton dengan luas lahan 1.152 ha dan produksi itu meningkat dibandingkan pada 2013 sebanyak 16.631 ton dengan luas lahan 678 ha. Bangorejo menyumbang 39\% dari total produksi buah naga di Banyuwangi atau setara 11.000 ton per ha dengan luas lahan mencapai 449 ha (Bisnis.com, 2015).

Kendala yang sering dihadapi sektor agribisnis adalah rendahnya posisi tawar petani selaku produsen komoditi pertanian ketika sampai dalam tahap pemasaran. Kurangnya informasi yang diakibatkan tidak adanya jejaring komunikasi dengan para pelaku agribisnis menyebabkan harga jual produk petani menjadi rendah. Lemahnya posisi tawar petani dapat mengancam keberlanjutan kegiatan usaha tani yang dimilikinya. Hal ini dapat disebabkan karena kurangnya keterlibatan berbagai pihak yang berkepentingan dalam agribisnis buah naga untuk dapat saling bekerjasama sesuai perannya masing-masing.

\section{Perumusan masalah}

Visi pembangunan daerah yang tertuang dalam RPJMD Kabupaten Banyuwangi 2010-2015 adalah Terwujudnya Masyarakat Banyuwangi yang Mandiri, Sejahtera dan Berakhlak Mulia Melalui Peningkatan Perekonomian dan Kualitas Sumber Daya Manusia dimana diturunkan ke dalam beberapa misi. Misi III yaitu "Mewujudkan daya saing ekonomi daerah melalui pertumbuhan ekonomi yang berkualitas dan berkelanjutan berbasis kearifan lokal", dimana misi ini memiliki sasaran-saran sebagai berikut: (a) meningkatnya daya saing daerah dan kemandirian ekonomi berbasis pertanian, (b) Meningkatnya industri olahan dan kreatif berbasis pertanian, (c) Termanfaatkannya fungsi ekologi, ekonomi dan sosial hutan (pertanian dalam arti luas), (d) Meningkatnya investasi di daerah baik PMA maupun PMDN, (e) Meningkatnya pemanfaatan potensi pariwisata, (f) Meningkatnya profesionalisme pengelolaan Koperasi dan UMKM, (g) Meningkatnya jejaring antar daerah, propinsi dan pusat serta jejaring pelaku ekonomi, dan (h) Tersusunnya regulasi yang berhubungan dengan kompetisi kegiatan ekonomi didaerah. 
Disusunnya strategi tersebut diharapkan buah naga yang menjadi salah satu komoditas unggulan sektor pertanian dapat dijadikan sebagai salah satu sektor penggerak kegiatan agribisnis di Kabupaten Banyuwangi. Berbagai pihak tentunya dilibatkan dalam kegiatan agribisnis, terutama dalam hal ini adalah para stakeholder. Meskipun peran dan kepentingan masing-masing stakeholder berbeda-beda, tetapi mutlak harus diperhitungkan dalam Kegiatan agribisnis buah naga di Kecamatan Bangorejo Kabupaten Banyuwangi.

1. Siapa saja stakeholder yang terlibat dalam Kegiatan agribisnis buah naga di Kecamatan Bangorejo Kabupaten Banyuwangi dan bagaimana hubungan antar stakeholder berdasarkan Tupoksi dan aturan kelembagaan yang ada?

2. Apa saja kebutuhan masing-masing stakeholder terkait dengan Kegiatan agribisnis buah naga di Kecamatan Bangorejo Kabupaten Banyuwangi?

3. Bagaimana peran stakeholder dalam keberlanjutan agribisnis buah naga di Kecamatan Bangorejo Kabupaten Banyuwangi?

\section{Tujuan}

Penelitian ini bertujuan untuk merumuskan mekanisme hubungan antar stakeholder dalam kegiatan agribisnis buah naga di Kecamatan Bangorejo Kabupaten Banyuwangi. Untuk mencapai tujuan tersebut maka dilakukan beberapa analisis, antara lain:

1. Stakeholder yang terlibat berdasarkan pengaruh dan kepentingannya dalam kegiatan agribisnis buah naga di Kecamatan Bangorejo Kabupaten Banyuwangi.

2. Kebutuhan stakeholder dalam kegiatan agribisnis buah naga di Kecamatan Bangorejo Kabupaten Banyuwangi.

3. Peran stakeholder dalam keberlanjutan agribisnis buah naga di Kecamatan Bangorejo Kabupaten Banyuwangi.

\section{METODE PENELITIAN}

\section{Lokasi dan waktu}

Penelitian ini dilaksanakan pada salah satu sentra agribisnis buah naga yang terletak di Kecamatan Bangorejo Kabupaten Banyuwangi. Penelitian ini dilaksanakan selama tiga bulan yang dimulai pada Bulan Agustus sampai dengan Oktober 2015.

\section{Teknik pengumpulan data}

Pengumpulan data dilakukan melalui kegiatan wawancara dengan sejumlah informan kunci seperti Koordinator BPP Kecamatan Bangorejo Kabupaten Banyuwangi, staf PPL petani pemilik lahan buah naga dan Staf Bappeda dimaksudkan untuk mendapatkan gambaran mengenai pihak-pihak (stakeholder) yang dapat terlibat dalam kegiatan agribisnis buah naga di Kecamatan Bangorejo Kabupaten Banyuwangi.

Kabupaten Banyuwangi selaku wakil dari Pemerintah Daerah. Kegiatan wawancara ini Kecamatan Bangorejo Kabupaten Banyuwangi, Kepala Bidang Hortikultura Dinas Pertanian, Kehutanan, Perkebunan Kabupaten Banyuwangi, Selain melakukan wawancara dengan sejumlah informan kunci, pengumpulan data juga dilakukan melalui kegiatan Focus Group Discussion (FGD) yang diikuti oleh petani pemilik lahan buah naga, staf PPL Kecamatan Bangorejo Kabupaten Banyuwangi, Ketua Gapoktan Kecamatan Bangorejo Kabupaten Banyuwangi, Kepala Bidang Hortikultura Dinas Pertanian, Kehutanan, Perkebunan Kabupaten Banyuwangi, dan ketua serta pengurus Kelompok Tani. Kegiatan FGD ini dimaksudkan memetakan stakeholders berdasarkan pengaruh (power) dan kepentingannya (interest), serta merumuskan peran-peran yang dapat dilakukan dalam mendukung tujuan pengembangan agribisnis buah naga di Kecamatan Bangorejo Kabupaten Banyuwangi.

\section{Analisis data}

Data yang dikumpulkan dianalisis dengan teknik analisis stakeholders secara kualitatif (Bracke, et al, 2005; Reed et al, 2009; dan Meyers, 2005). Analisis stakeholders secara kualitatif digunakan untuk menjelaskan stakeholders yang terlibat dalam kegiatan agribisnis buah naga di Kecamatan Bangorejo Kabupaten Banyuwangi, kepentingan (interest) dan pengaruh (power) setiap stakeholders serta untuk menjelaskan peran stakeholders dalam mendukung tujuan keberlanjutan kegiatan agribisnis buah naga di Kecamatan Bangorejo Kabupaten Banyuwangi.

\section{HASIL DAN PEMBAHASAN}

\section{Identifikasi stakeholder}

Kegiatan agribisnis buah naga di Kecamatan Bangorejo Kabupaten Banyuwangi melibatkan 8 (delapan) stakeholder. Stakeholder tersebut berasal dari instansi pemerintah daerah, Badan Usaha Milik Negara (BUMN) ataupun swasta, dan kelompok masyarakat. Hasil identifikasi stakeholder yang terlibat dalam kegiatan agribisnis buah naga di Kecamatan Bangorejo Kabupaten Banyuwangi disajikan pada Tabel 1.

Tabel 1. Daftar stakeholder yang terlibat dalam kegiatan agribisnis buah naga di Kecamatan Bangorejo Kabupaten Banyuwangi 


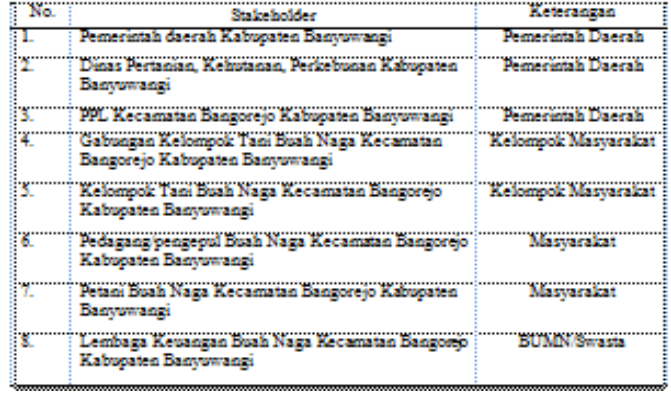

1.1 Instansi pemerintah

1.1.1 Pemerintah daerah Kabupaten Banyuwangi Kewenangan instansi pemerintah dalam kegiatan agribisnis buah naga di Kecamatan Bangorejo Kabupaten Banyuwangi yang meliputi merumuskan kebijakan, pembangunan sarana dan prasarana, pemberdayaan masyarakat serta penyediaan data dan informasi. Instansi pemerintah yang terlibat dalam agribisnis buah naga di Kecamatan Bangorejo Kabupaten Banyuwangi adalah Pemerintah daerah Kabupaten Banyuwangi, Dinas Pertanian, Kehutanan, Perkebunan Kabupaten Banyuwangi dan PPL Kecamatan Bangorejo Kabupaten Banyuwangi.

\subsubsection{Dinas Pertanian, Kehutanan, Perkebunan} Kabupaten Banyuwangi

Dinas Pertanian, Kehutanan, Perkebunan Kabupaten Banyuwangi merupakan salah satu instansi pemerintah kegiatan agribisnis buah naga di Kecamatan Bangorejo Kabupaten Banyuwangi yang memiliki berbagai pengaruh dan kepentingannya, terutama dalam bidang pertanian. Tugas pokok dan fungsi (Tupoksi) Dinas Pertanian, Kehutanan, Perkebunan Kabupaten Banyuwangi yang dijabarkan dalam Peraturan Bupati Banyuwangi Nomor 43 Tahun 2011 untuk melaksanakan urusan pemerintahan daerah di bidang pertanian, kehutanan dan perkebunan. Bidang pertanian yang dibawahi oleh Dinas Pertanian, Kehutanan, Perkebunan Kabupaten Banyuwangi adalah Bidang Pertanian Tanaman Pangan, Bidang Hortikultura, Bidang Kehutanan, serta Bidang Perkebunan. Komoditi buah naga dalam hal ini menjadi tupoksi Bidang Hortikultura. Bidang Hortikultura mempunyai tugas pokok melaksanakan kegiatan pembinaan dan pengembangan komodite hortikultura (tanaman buah-buahan, sayuran, tanaman obat dan tanaman hias), pembinaan pasca panen dan pengolahan hasil hortikultura.

\subsubsection{PPL Kecamatan Bangorejo Kabupaten}

Banyuwangi

Penyuluh Pertanian Lapang (PPL) adalah orang yang mengemban tugas memberikan dorongan kepada petani agar mau mengubah cara befikir, cara kerja dan cara hidup yang lebih sesuai dengan perkembangan jaman, perkembangan teknologi pertanian yang lebih maju. Seorang penyuluh pertanian dalam melaksanakan tugasnya mempunyai tiga peranan, yaitu sebagai pendidik, sebagai pemimpin, dan sebagai penasehat (Kartasapoetra, 1994).

\subsection{Badan Usaha Milik Negara (BUMN) ataupun} swasta

Badan Usaha Milik Negara (BUMN) atau swasta yang terlibat dalam kegiatan agribisnis buah naga di Kecamatan Bangorejo Kabupaten Banyuwangi adalah lembaga keuangan, dimana dalam hal ini dapat berupa lembaga keuangan milik pemerintah ataupun swasta yang berperan dalam kegiatan pembiayaan pelaku agribisnis buah naga di Kecamatan Bangorejo Kabupaten Banyuwangi.

\subsubsection{Lembaga keuangan}

Lembaga keuangan yang terlibat dalam kegiatan agribisnis buah naga dapat berasal dari lembaga milik pemerintah maupun swasta. Perwakilan lembaga keuangan dalam hal ini adalah Bank Jatim yang telah mengeluarkan kredit modal kerja KKPE bagi petani buah naga yang disalurkan melalui media Gabungan Kelompok Tani yang telah terbentuk.

\subsection{Kelompok Masyarakat}

Kelompok masyarakat yang terlibat dalam kegiatan agribisnis buah naga di Kecamatan Bangorejo Kabupaten Banyuwangi adalah Gabungan Kelompok Tani (Gapoktan) dan Kelompok Tani. Kelompok masyarakat yang terkait dengan kegiatan agribisnis buah naga di Kecamatan Bangorejo Kabupaten Banyuwangi memiliki peran dalam meningkatkan efektifitas dan efisiensi penyelenggaraan penyuluhan serta meningkatkan kapasitas poktan dan gapoktan melalui pengembangan kerjasama dalam bentuk jejaring dan kemitraan.

1.3.1.1 Gabungan Kelompok Tani Buah Naga

Kecamatan Bangorejo Kabupaten

Banyuwangi

Gabungan Kelompoktani yang selanjutnya disebut gapoktan adalah kumpulan beberapa kelompoktani yang bergabung dan bekerjasama untuk meningkatkan skala ekonomi dan efisiensi usaha, dalam hal ini adalah adanya kesamaan usaha tani buah naga di Kecamatan Bangorejo Kabupaten Banyuwangi.

\subsubsection{Kelompok Tani Buah Naga Kecamatan}

Bangorejo Kabupaten Banyuwangi

Kelompoktani yang selanjutnya disebut poktan adalah kumpulan petani/peternak/pekebun yang dibentuk atas dasar kesamaan kepentingan; kesamaan kondisi lingkungan sosial, ekonomi, dan sumberdaya; kesamaan komoditas; dan keakraban untuk meningkatkan dan mengembangkan usaha anggota. Kelompok tani yang berada di Kecamatan Bangorejo memiliki lingkup usaha yang umum 
untuk semua komoditas pertanian dan tidak hanya terbatas pada usaha tani buah naga, namun yang diambil sebagai narasumber dalam penelitian ini adalah kelompok tani yang menjalankan usaha buah naga.

\subsection{Masyarakat}

Peran masyarakat berkaitan dengan kegiatan agribisnis buah naga di Kecamatan Bangorejo Kabupaten Banyuwangi adalah sebagai pelaku usaha, yang melakukan usaha sarana produksi pertanian, pengolahan dan pemasaran hasil pertanian, serta jasa penunjang pertanian yang berkedudukan di wilayah hukum Republik Indonesia. Masyarakat juga mendapatkan penyuluhan baik dari instansi pemerintah maupun kelompok masyarakat tentang cara mengakses informasi pasar, teknologi, permodalan, dan sumberdaya lainnya, sebagai upaya untuk meningkatkan produktivitas, efisiensi usaha, pendapatan, dan kesejahteraannya, serta meningkatkan kesadaran dalam pelestarian fungsi lingkungan hidup.

\subsubsection{Petani Buah Naga Kecamatan Bangorejo}

Kabupaten Banyuwangi

Petani buah naga dalam hal ini adalah Warga Negara Indonesia perseorangan dan/atau beserta keluarganya yang melakukan usahatani di bidang tanaman buah naga di Kecamatan Bangorejo Kabupaten Banyuwangi.

\subsubsection{Pedagang/pengepul Buah Naga}

Kecamatan Bangorejo Kabupaten

Banyuwangi

Pedagang/pengepul Buah Naga

Kecamatan Bangorejo Kabupaten Banyuwangi adalah setiap orang yang melakukan kegiatan distribusi dan pemasaran produk buah naga di Kecamatan Bangorejo Kabupaten Banyuwangi.

\section{Klasifikasi Stakeholder}

Klasifikasi stakeholder dibedakan menurut tingkat pengaruh dan kepentingan dalam kegiatan agribisnis buah naga di di Kecamatan Bangorejo Kabupaten Banyuwangi. Pengukuran tingkat pengaruh stakeholder dalam kegiatan agribisnis buah naga di di Kecamatan Bangorejo Kabupaten Banyuwangi menggunakan lima variabel yang meliputi kekuatan kondisi, kekuatan kelayakan, kekuatan kompensasi, kekuatan individu dan kekuatan organisasi (Galbraith 1983 diacu dalam Reed et al. 2009). Pengukuran tingkat kepentingan stakeholder dalam kegiatan agribisnis buah naga di di Kecamatan Bangorejo Kabupaten Banyuwangi menggunakan lima variabel yang meliputi keterlibatan stakeholder, manfaat yang diperoleh stakeholder, bentuk kewenangan stakeholder, program kerja stakeholder dan tingkat ketergantungan stakeholder dalam kegiatan agribisnis buah naga di di Kecamatan Bangorejo Kabupaten Banyuwangi.

Tabel 2. Hasil Perhitungan nilai tingkat pengaruh stakeholder

\begin{tabular}{|c|c|c|c|c|c|c|}
\hline 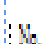 & \multirow{2}{*}{ Gether } & \multicolumn{4}{|c|}{ M: } & \multirow{2}{*}{ Tat } \\
\hline & & & $n:$ & H it & in & \\
\hline & 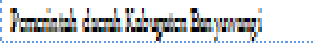 & 4 & 1 & 14 & 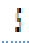 & H \\
\hline & 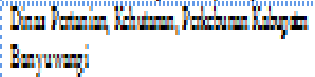 & 1 & 1 & 1 & 4 & it \\
\hline & 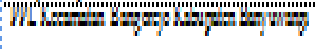 & 1 & 1 & 14 & 4 & it \\
\hline & 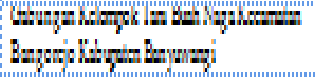 & 1 & $!$ & 1 & 1 & !! \\
\hline & 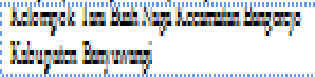 & 1 & 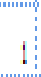 & 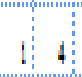 & 1 & 11 \\
\hline 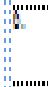 & 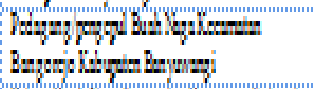 & 1 & $:$ & 1 & 1 & it \\
\hline & 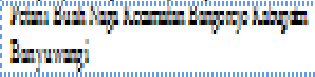 & 1 & $!$ & 1 & 1 & 10 \\
\hline itidi: & 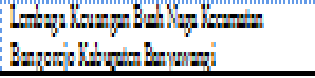 & 1 & 2 & : & 1 & 10 \\
\hline
\end{tabular}

Tabel 3. Hasil Perhitungan nilai tingkat kepentingan stakeholder

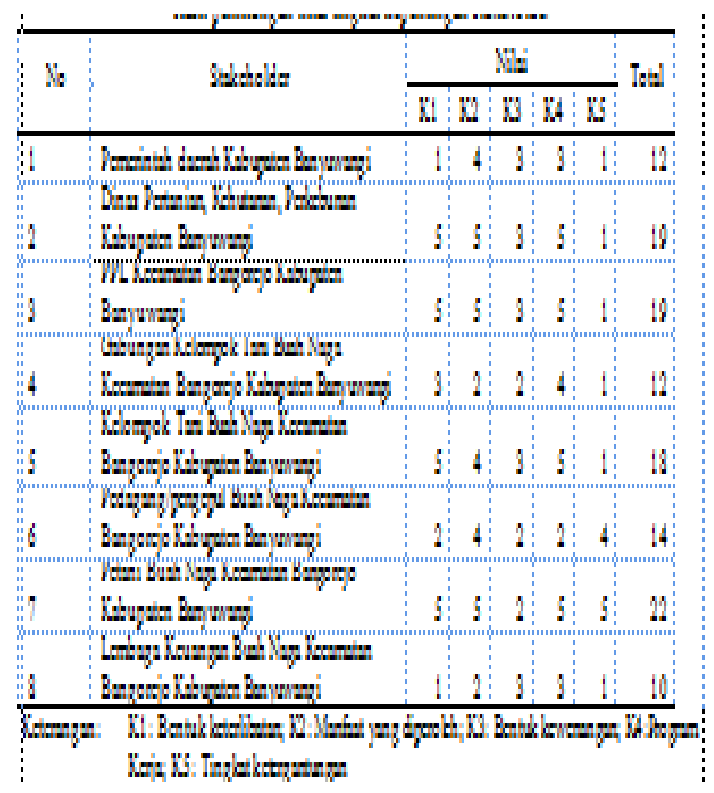

Hasil analisis stakeholder diklasifikasikan menurut tingkat pengaruh dan kepentingan dengan menggunakan matriks menurut Reed et al. (2009) dapat dilihat pada Gambar 4. Matriks pengaruh dan kepentingan stakeholder tersebut menunjukkan bahwa masing-masing stakeholder memiliki klasifikasi yang berbeda sesuai dengan tingkat pengaruh dan kepentingannya dalam kegiatan agribisnis buah naga di di Kecamatan Bangorejo Kabupaten Banyuwangi. 


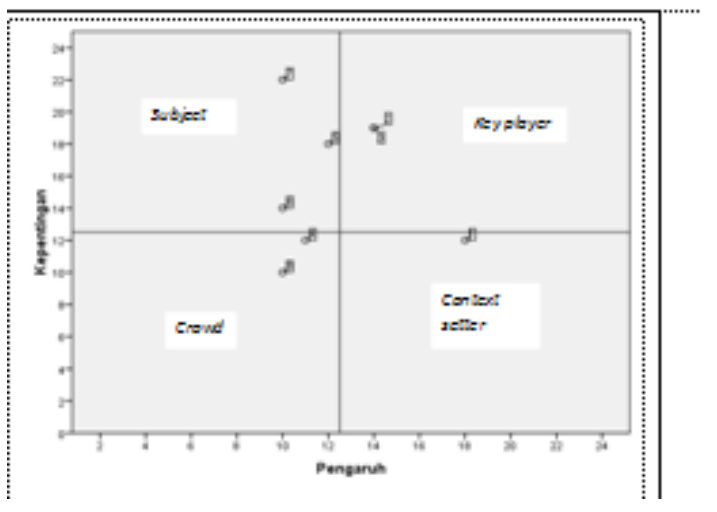

Gambar 1. Matriks pengaruh dan kepentingan stakeholder

\subsection{Key Player}

Stakeholder yang termasuk dalam kelompok key player adalah Dinas Pertanian, Kehutanan, Perkebunan Kabupaten Banyuwangi dan PPL Kecamatan Bangorejo Kabupaten Banyuwangi. Key player merupakan klasifikasi stakeholder yang memiliki pengaruh dan kepentingan yang tinggi dalam kegiatan agribisnis buah naga di Kecamatan Bangorejo Kabupaten Banyuwangi. Hal ini sesuai dengan tugas pokok yang dimiliki oleh Dinas Pertanian, Kehutanan, Perkebunan Kabupaten Banyuwangi sebagai instansi pemerintah daerah yang telah diberikan mandat dalam melaksanakan urusan pemerintahan daerah di bidang pertanian, kehutanan dan perkebunan. Key player dalam kegiatan agribisnis buah naga di di Kecamatan Bangorejo Kabupaten Banyuwangi selanjutnya adalah PT PPL Kecamatan Bangorejo Kabupaten Banyuwangi. PPL Kecamatan Bangorejo Kabupaten Banyuwangi merupakan kepanjangan tangan dari Dinas Pertanian, Kehutanan, Perkebunan Kabupaten Banyuwangi yang berperan dalam melakukan kegiatan penyuluhan pertanian kepda petani sebagai pelaku usaha tani buah naga agar mereka mau dan mampu menolong dan mengorganisasikan dirinya dalam mengakses informasi pasar, teknologi, permodalan, dan sumberdaya lainnya, sebagai upaya untuk meningkatkan produktivitas, efisiensi usaha, pendapatan, dan kesejahteraannya, serta meningkatkan kesadaran dalam pelestarian fungsi lingkungan hidup. Peran penting kedua stakeholder tersebut memiliki peran utama dalam upaya mengembangkan kegiatan agribisnis buah naga di Kecamatan Bangorejo Kabupaten Banyuwangi.

\subsection{Subject}

Stakeholder yang termasuk dalam kelompok subject adalah petani buah naga, kelompok Tani buah naga, serta pedagang buah naga di Kecamatan Bangorejo Kabupaten Banyuwangi. Kelompok subject merupakan klasifikasi stakeholder yang memiliki kepentingan tinggi namun pengaruh yang rendah. Ketiga stakeholder tersebut memiliki tujuan yang sama, yaitu meningkatkan peran petani dalam kegiatan agribisnis buah naga agar lebih produktif dan sekaligus menerima manfaat yang positif. Masing-masing stakeholder tersebut memiliki kepentingan tinggi, dikarenakan semua kegiatan yang dilakukan bertujuan untuk meningkatkan nilai tambah dari aktivitas produksi buah naga. Namun kelompok subject memiliki pengaruh yang kecil karena hanya melakukan hubungan kerjasama dengan kelompok tani setempat dan dibawah naungan Dinas Pertanian, Kehutanan, Perkebunan Kabupaten Banyuwangi kecuali pada pedagang/pengepul buah naga.

\subsection{Context setter}

Stakeholder yang termasuk dalam kelompok context setter adalah Pemerintah daerah Kabupaten Banyuwangi. Kelompok context setter merupakan klasifikasi stakeholder yang memiliki kepentingan rendah namun pengaruh yang tinggi. Pemerintah daerah Kabupaten Banyuwangi dilibatkan dalam perancangan kebijakan di bidang pertanian. Keterlibatan perancangan kebijakan tersebut dalam bentuk penyusunan rencana strategis maupun rencana pembangunan jangka panjang maupun menengah di bidang pengembangan potensi unggulan pertanian guna meningkatkan perekonomian dan kesejahteraan masyarakat. Hal ini menyebabkan Pemerintah daerah Kabupaten Banyuwangi dapat memberikan pengaruh terhadap pengalokasian anggaran daerah melalui penanaman modal di bidang pertanian.

\subsection{Crowd}

Stakeholder yang termasuk dalam kelompok crowd adalah Gabungan Kelompok Tani Buah Naga Kecamatan Bangorejo Kabupaten Banyuwangi dan Lembaga Keuangan Buah Naga Kecamatan Bangorejo Kabupaten Banyuwangi. Kelompok crowd merupakan klasifikasi stakeholder yang memiliki pengaruh dan kepentingan rendah. Para stakeholder tersebut masih belum berperan secara signifikan dalam kegiatan agribisnis buah naga di Kecamatan Bangorejo Kabupaten Banyuwangi, dikarenakan hanya berperan dalam kegiatan penyediaan kebutuhan pembiayaan dan koordinasi antar kelompok tani. 


\section{Kebutuhan Stakeholder dalam keberlanjutan agribisnis buah naga}

Stakeholder yang terlibat tentunya memiliki kebutuhan yang perlu untuk dipenuhi terkait dengan kegiatan agribisnis buah naga sesuai dengan Tupoksi dan aturan kelembagaannya. Adapun kebutuhan masing-masing stakeholder dalam kegiatan agribisnis buah naga di Kecamatan Bangorejo Kabupaten Banyuwangi disajikan dalam Tabel 4.

Tabel 5. Kelompok Kebutuhan stake holder

Tabel 4. Kebutuhan Stake Holer

\begin{tabular}{|c|c|c|}
\hline Ma & 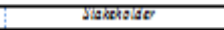 & Refunata \\
\hline !r & 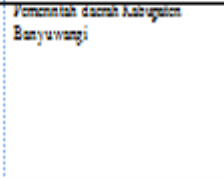 & 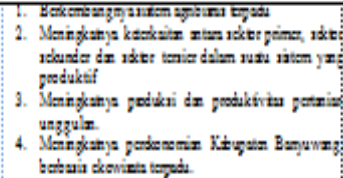 \\
\hline : & 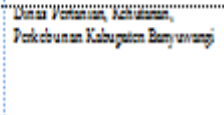 & 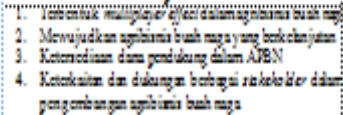 \\
\hline in' & 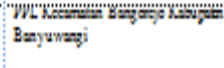 & 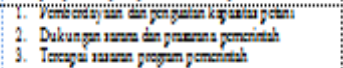 \\
\hline क्ष" & 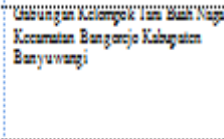 & 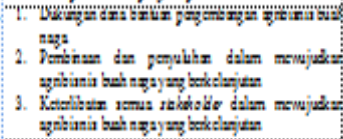 \\
\hline 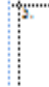 & 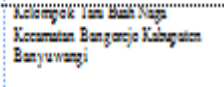 & 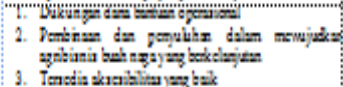 \\
\hline 6 & 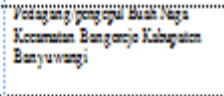 & 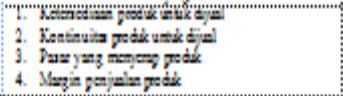 \\
\hline & 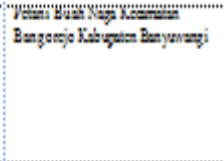 & 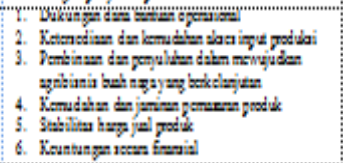 \\
\hline i. & 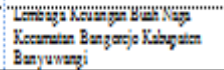 & 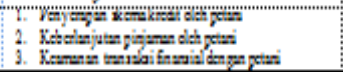 \\
\hline
\end{tabular}

Identifikasi kebutuhan masing-masing stakeholder dapat dikelompokkan menjadi 7 kelompok kebutuhan berdasarkan kesamaan kebutuhan. Adapun 7 kelompok kebutuhan yang terdiri atas partisipasi, investasi, regulasi, kontinuitas, advokasi, infrastruktur, dan fasilitas. Kelompok kebutuhan masing-masing stakeholder disajikan pada Tabel 5.

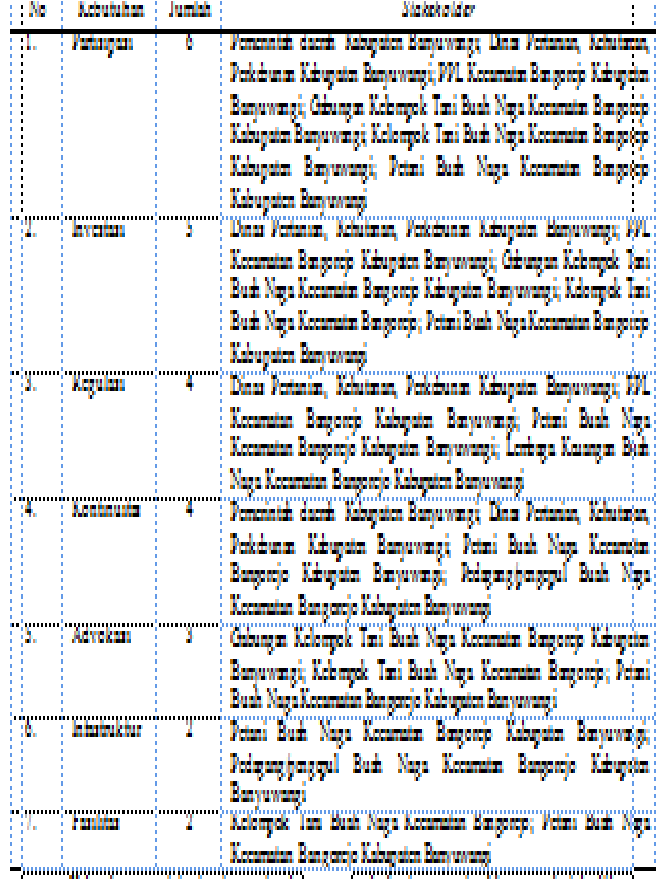

Kebutuhan partisipasi, investasi dan regulasi serta kontinuitas dapat dikatakan sebagai kebutuhan prioritas stakeholder dalam agribisnis buah naga di Kecamatan Bangorejo Kabupaten Banyuwangi. Kebutuhan investasi merupakan kebutuhan utama dalam upaya mendukung dan melaksanakan kegiatan yang berkaitan dengan agribisnis buah naga. Sebagian besar kelompok masyarakat dan masyarakat menginginkan partisipasi dalam bentuk kerjasama maupun kontribusi dalam kegiatan agribisnis buah naga agar dapat meningkatkan pendapatan. Regulasi dibutuhkan dalam mengatur masing-masing stakeholder agar dapat berperan sesuai porsinya dalam kegiatan agribisnis buah naga di Kecamatan Bangorejo Kabupaten Banyuwangi. Apabila terdapat regulasi maka tidak ada stakeholder yang merasa dirugikan, sehingga kontinuitas dapat tercapai. Kelompok masyarakat petani pelaku agribisnis buah naga membutuhkan advokasi mengenai pelaksanaan teknis budidaya, kelembagaan, serta inovasi teknologi, agar petani dapat mengetahui peran sertanya dan mengetahui kebutuhan pasar sehingga dapat mempersiapkan segala sesuatu baik yang bersifat menguntungkan maupun hanya bersifat mendukung saja. Kelompok masyarakat petani membutuhkan bimbingan agar dapat mengetahui peran dan batasan mana yang harus dilakukan atau diambil dalam mendukung keberlanjutan agribisnis buah naga. 


\section{Peran Stakeholder dalam keberlanjutan agribisnis buah naga}

Keterlibatan sejumlah stakeholders dengan segala potensi yang dimiliki dan peran yang dapat dilakukannya diperlukan guna mencapai tujuan bersama. Beberapa peran yang diharapkan dilakukan oleh setiap stakeholders dalam mendukung keberlanjutan agribisnis buah naga adalah seperti pada tabel 6 .

Tabel 6.

Peran Stakeholder yang seharusnya terlibat dalam keberlanjutan agribisnis buah naga di Kecamatan Bangorejo Kabupaten Banyuwangi

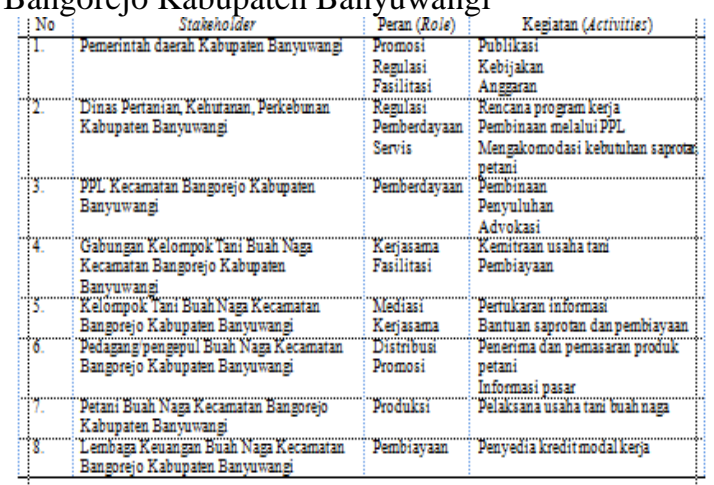

Saran

Dinas Pertanian, Kehutanan, Perkebunan Kabupaten Banyuwangi dan PPL Kecamatan Bangorejo Kabupaten Banyuwangi selaku stakeholder utama hendaknya dapat menjalankan perannya sesuai tupoksi yang diamanatkan dalam mencapai tujuan sesuai visi pembangunan daerah khususnya memaksimalkan potensi Kecamatan Bangorejo yang memiliki komoditi unggulan yaitu buah naga sebagai penggerak sektor agribisnis. Hal itu dapat terwujud apabila terjalin komunikasi dan koordinasi yang baik antar stakeholder sehingga tercapai kesamaan persepsi demi mewujudkan tujuan bersama.

\section{KESIMPULAN DAN SARAN}

\section{Kesimpulan}

1. Stakeholder yang terlibat berdasarkan pengaruh dan kepentingannya dalam kegiatan agribisnis buah naga di Kecamatan Bangorejo Kabupaten Banyuwangi terdiri dari Pemerintah daerah Kabupaten Banyuwangi, Dinas Pertanian, Kehutanan, Perkebunan Kabupaten Banyuwangi, PPL Kecamatan Bangorejo Kabupaten Banyuwangi, Gabungan Kelompok Tani Buah Naga Kecamatan Bangorejo Kabupaten Banyuwangi, Kelompok Tani Buah Naga Kecamatan Bangorejo Kabupaten Banyuwangi, Kelompok Tani Buah Naga Kecamatan Bangorejo Kabupaten Banyuwangi, Pedagang/pengepul Buah Naga Kecamatan Bangorejo Kabupaten
Banyuwangi, Petani Buah Naga Kecamatan Bangorejo Kabupaten Banyuwangi, dan Lembaga Keuangan Buah Naga Kecamatan Bangorejo Kabupaten Banyuwangi. Stakeholder yang termasuk dalam kelompok key player adalah Dinas Pertanian, Kehutanan, Perkebunan Kabupaten Banyuwangi dan PPL Kecamatan Bangorejo Kabupaten Banyuwangi

2. Kebutuhan stakeholder dikelompokkan menjadi 6 kelompok kebutuhan yaitu partisipasi, investasi, regulasi, kontinuitas, advokasi, infrastruktur, dan fasilitas. Kebutuhan utama stakeholder dalam mewujudkan keberlanjutan kegiatan agribisnis buah naga di Kecamatan Bangorejo Kabupaten Banyuwangi adalah kebutuhan partisipasi, investasi dan regulasi yang disertai dengan kebutuhan kontinuitas.

3. Keterlibatan stakeholders memiliki peran masing-masing dalam mendukung keberlanjutan kegiatan agribisnis buah naga di Kecamatan Bangorejo Kabupaten Banyuwangi, dimana Dinas Pertanian, Kehutanan, Perkebunan Kabupaten Banyuwangi dan PPL Kecamatan Bangorejo Kabupaten Banyuwangi sebagai stakeholder kunci seharusnya memiliki peran dalam hal regulasi, pemberdayaan, dan servis.

Saran

Dinas Pertanian, Kehutanan, Perkebunan Kabupaten Banyuwangi dan PPL Kecamatan Bangorejo Kabupaten Banyuwangi selaku stakeholder utama hendaknya dapat menjalankan perannya sesuai tupoksi yang diamanatkan dalam mencapai tujuan sesuai visi pembangunan daerah khususnya memaksimalkan potensi ' Bangorejo yang memiliki komoditi unggulan yaitu buah naga sebagai penggerak sektor agribisnis. Hal itu dapat terwujud apabila terjalin komunikasi dan koordinasi yang baik antar stakeholder sehingga tercapai kesamaan persepsi demi mewujudkan tujuan bersama.

\section{DAFTAR PUSTAKA}

Charina, et.al. 2012. Kajian Bisnis Sosial Pedagang Perantara dalam Upaya Pengembangan Hortikultura di Jawa Barat. Jurnal Sosial Ekonomi Pertanian, Volume 1, Nomor 1, April 2012, hlm 33-51. Jurusan Sosial Ekonomi Pertanian Universitas Padjadjaran 
Hermanto dan Swastika, K. S., Dewa. 2011. Penguatan Kelompok Tani: Langkah Awal Peningkatan Kesejahteraan Petani. Analisis Kebijakan Pertanian Volume No. 4 Desember 2011: 371-390

Kusumedi, P dan Bisjoe, A.R.H. 2010. Analisis Stakeholder dan Kebijakan Pembangunan KPH Model Maros di Propinsi Sulawesi Selatan. Jurnal Analisis Kebijakan Kehutanan, 7(3), 179-193.

Nuryati, Sri dan Swastika, K. S., Dewa. 2011. Peran Kelompok Tani dalam Penerapan Teknologi Pertanian. Forum Penelitian Agro ekonomi Volume 29 No. 2 Desember 2011: 115-128

Pusat Kebijakan Perdagangan Dalam Negeri Badan Pengkajian dan Pengembangan Kebijakan Perdagangan Kementerian Perdagangan republik Indonesia. 2014. Kajian Peran Pedagang Perantara (Middleman) dalam Perdagangan Dalam Negeri. Pusat Kebijakan Perdagangan Dalam Negeri Badan Pengkajian dan Pengembangan Kebijakan Perdagangan Kementerian Perdagangan republik Indonesia. Jakarta

Reed, M.S. 2008. Stakeholder Participation for Environmental Management: A Literature Review. Biological Conservation, 141, 2417-2431.

Reed M, Graves A, Dandy N, Posthumus H, Hubacek K, Morris J, Prell C, Quinn CH, Stringer LC. 2009. Who's Nad Why? A Typology of Stakeholder Analysis Methods for Natural Resource Management. Journal of Environmental Management 90:1933-1949.

Redono, Cucak. 2012. Peran Gabungan Kelompok Tani (Gapoktan) dalam Mewujudkan Kelompok Tani yang kuat dan Mandiri. Jurnal Ilmu-Ilmu Pertanian Volume 15 Nomor 1, Juli 2012. Sekolah Tinggi Penyuluhan Pertanian Magelang .Jurusan Penyuluhan Pertanian Yogyakarta

Saptana, et. al. 2013. Strategi PercepatanTransformasi Kelembagaan Gapoktan dan Lembaga Keuangan Mikro Agribisnis Dalam Memperkuat Ekonomi Di Perdesaan. Jurnal Manajemen \& Agribisnis, Vol. 10 No. 1, Maret 2013
Saridewi, T. R dan Siregar, A. N. 2010. Hubungan Antara Peran Penyuluh Dan Adopsi Teknologi oleh Petani terhadap Peningkatan Produksi Padi di Kabupaten Tasikmalaya. Jurnal Penyuluhan Pertanian Vol. 5 No. 1, Mei 2010

Schmerr K. 2009. Stakeholder Anallysis Guidelines. http:/www.lanchsr.org [1 Mei 2012]

Supanggih, Dhianon dan Widodo, Slamet. 2013. Aksesibilitas Petani terhadap Lembaga Keuangan (Studi Kasus Pada Petani di Desa Sidodadi Kecamatan Sukosewu Kabupaten Bojonegoro). Jurnal Agriekonomika Volume 2 Nomor 2 Oktober 2013

Syahyuti. 2007. Kebijakan pengembangan gabungan kelompok tani (Gapoktan) sebagai kelembagaan ekonomi di perdesaan. Analisis Kebijakan Pertanian 5(1):15-36.

Syahyuti, et.al. 2014. Kajian Peran Organisasi Petani dalam Mendukung Pembangunan Pertanian. Laporan Akhir Penelitian. Pusat Analisis Sosial Ekonomi dan Kebijakan Pertanian Badan Penelitian dan Pengembangan Pertanian Kementerian Pertanian.

Wakka, A. K. 2014. Analisis Stakeholders Pengelolaan Kawasan Hutan dengan Tujuan Khusus (Khdtk) Mengkendek, Kabupaten Tana Toraja, Provinsi Sulawesi Selatan. Jurnal Penelitian Kehutanan Wallacea Vol. 3 No.1, April $2014: 47$ - 55

Yekti, Ananti. 2010. Peranan Lembaga Keuangan Formal dan Informal Bagi Masyarakat Pertanian di Pedesaan. Jurnal Ilmu-ilmu Pertanian Volume 6, Nomor 2, Desember 2010. Sekolah Tinggi Penyuluhan Pertanian Magelang . Jurusan Penyuluhan Pertanian Yogyakarta

Zulfikar, Muamar. 2013. Analisis Stakeholder dalam Pengelolaan Wisata Alam di Kabupaten Brebes Provinsi Jawa Tengah. Skripsi. Departemen Konservasi Sumberdaya Hutan dan Ekowisata Fakultas Kehutanan Institut Pertanian Bogor 